\title{
Remove of Phenolic Compounds in Water by Low-Temperature Plasma: A Review of Current Research
}

\author{
Jufang ZHANG ${ }^{\mathbf{1}}$, Jierong CHEN ${ }^{\mathbf{1}}$, Xiaoyong LI $^{\mathbf{2}}$ \\ ${ }^{1}$ School of Energy and Power Engineering, Xi' an Jiao Tong University, Xi'an, China \\ ${ }^{2}$ School of Science, Xi'an Jiao Tong University, Xi'an, China \\ E-mail:jrchen@mail.xjtu.edu.cn \\ Received March 19, 2009; revised April 21, 2009; accepted April 23, 2009
}

\begin{abstract}
Phenolic compounds have very strong toxicity, so it has been paid sharply attention to find an effective way of controlling the wastewater containing phenolic compounds. The work on this subject done by domestic and overseas scholars is studied in this paper, and the progress of researches on low-temperature plasma treatment is summarized through the electrical discharge types, mechanism, kinetics of phenolic compounds decomposition and combination of several methods with low-temperature plasma treatment. In addition, the crucial problem and the developing tendency on low-temperature plasma treatment for phenol-bearing wastewater are briefly discussed.
\end{abstract}

Keywords: Low-Temperature Plasma Treatment, Phenolic Compounds, Types of Electrical Discharge, Mechanism, Kinetics, Combination of Several Methods

\section{Introduction}

Phenolic compounds are well-known disinfectants and sterilizers as well as raw materials for synthetic resin, dyes, pharmaceuticals, perfumes, pesticides, tanning agents, solvents or lubricating oils. Long-term exposure to phenol paralyzes the human central nervous system and damages kidneys and lungs [1]. They are the representatives of water soluble. Especially phenol, it is also classified as a teratogenic and carcinogenic agent. Thus, phenol is listed in water hazard class 2 in several countries. Biodegradability is only $90 \%$ in surface waters after seven days, and the aquatic toxicity of phenol (LC50) is $12 \mathrm{mg} \cdot \mathrm{L}^{-1}$ (Daphnia magna, $48 \mathrm{~h}$ ). In EU countries, the maximum concentration of phenol allowed in drinking water is $0.5 \mathrm{mg} \cdot \mathrm{L}^{-1}$ (Weber et al., 2008) [2].The removal of phenolic compounds from wastewater is one of the most critical and urgent topics in environmental research.

Plasma is a group of positive particles, negative particles, which includes positive ions, negative ions, electron, free radicals, and a variety of active radicals, etc. Because positive charge is equal to negative charge in this group, it is called plasma. Based on the particle temperature, plasma can be divided into two categories, namely ther- mal plasma, and non-thermal plasma (low-temperature plasma) [3]. As one of the potential advanced oxidation processes (AOPs), non-thermal plasma production during various discharges has long been exploited for water and wastewater purification. Owing to its virtue of producing in situ oxidative species $\left(\mathrm{OH} \cdot, \mathrm{H} \cdot, \mathrm{O} \bullet, \mathrm{H}_{2} \mathrm{O}_{2}, \mathrm{H}_{2}, \mathrm{O}_{2}, \mathrm{O}_{3}\right)$ as well as initiating a variety of chemical and physical processes(a high electric field, intense ultraviolet radiation, overpressure shock waves) [4-7] in water for decomposing toxic compounds, its operational simplicity (realized under the conditions of an ambient temperature and pressure), its variable reactor configuration, and its good-performance degradation of low-concentration organic compounds. This low-temperature plasma treatment has been of great interest in the field of environmental protection. In this review, electrical discharge types, mechanism, kinetics of phenolic compounds decomposition and combination of several methods with low-temperature plasma treatment will be presented.

\section{Types of Electrical Discharges}

Non-thermal plasma was produced during discharge in the gas, liquid or hybrid liquid-gas phase. Recently, many 
types of plasma processes have been developed for the removal of phenolic compounds from water, including pulsed electrical discharge, glow discharge plasma (GDP), gas-liquid gliding arc discharges.

\subsection{Pulsed High-Voltage Electrical Discharge}

A pulsed high-voltage electrical discharge can begin in gas phase close proximity to the liquid surface, liquid phase and gas-liquid phase. When in liquid, it produces spark, streamers and corona, which are called pulsed spark discharge (PSD), pulsed streamer corona discharge (PSCD), and pulseless corona discharge (PCD) respectively. When it discharges on surface of water (WSP), it can only produce corona, arc and so on [4].

\subsubsection{Gas Phase Discharge}

L. R. Grabowski et al. [8] studied the removal of phenol from a thin layer of water by creating pulsed corona discharges above the water (CAW). The CAW reactor was proved to be an effective source for ozone production, which is capable to remove $45 \%$ of phenol in $5 \mathrm{~min}$ of a $100 \mathrm{ml} 1 \mathrm{mM}$ batch. Sun et al. [9] found that the removal efficiency of phenol contaminants in the aqueous solution by plasma produced in gas phase discharge was higher when it came to the spark discharge than to the streamer corona discharge. But [4] the specific energy required to decompose phenol was higher in the WSP (Pulsed highvoltage discharges on the water surface) discharge mode than in the corona and streamer discharge modes, but the treatment time required for decomposition in the WSP mode was shorter than in the other modes.

\subsubsection{Liquid Phase Discharge}

For the pulsed high-voltage electrical discharge in liquid, there are three different types of reactors, which have rod-rod, rod-plate and wire-cylinder electrode constructions. Shinta et al. [10] studied the pulsed high voltage discharge in water and degradation properties of three different types of reactors. They found that of the three reactors (rod-rod and rod-plate, wire-cylinder), the highest phenol removal efficiency was obtained with the wire-cylinder reactor, while the removal efficiency with the rod-rod and rod-plate almost the same. Ilie Suarasan et al. [11] changed the traditional discharge rod-plate reactor in water to multipoint reactor, and studied many factors affecting the produce of $\mathrm{O}_{3}$. Wang Fangzheng et al. [12] researched a multi-needle-to-plate high voltage pulsed discharge plasma system to degrade phenol. They found that the degradation rate of phenol increases with the decrease of solution conductivity and electrode distance, but with the increase of gas bubbling. In the case of $100 \mathrm{~mL} \cdot \mathrm{min}^{-1}$ solution circulation rate, the degradation rate with $\mathrm{pH}$ value of 6.4 and electric conductivity of 100 $\mu \mathrm{s} / \mathrm{cm}$ reached $86.2 \%$ after 60 min treatment.
Chen, Y. S. et al. [13-15] made a series of study on the removal of phenolic compounds (phenol, 4-chlorphenol) in the aqueous solution with pulsed high-voltage corona discharge plasma. They studied the effects of various parameters on the removal efficiency, and found that phenol degradation can be raised considerably by increasing the peak voltage of the pulsed discharge and the repetition rate of pulse, or by increasing $\mathrm{pH}$ of the aqueous solution. Furthermore, decreasing the diameter of discharge electrode and electric conductivity of the aqueous solution can increase the degradation efficiency. The addition of gas, especially oxygen through the hollow needle electrode, and of $\mathrm{FeSO}_{4}$ to the aqueous solution of phenol is found to significantly enhance phenol degradation. L. R. Grabowski et al.

Yongjun Shen et al. [16] investigated the processes of phenol degradation by pulsed electrical discharges under several kinds of discharge atmospheres (oxygen, argon, nitrogen and ozone) and chemical catalysts (ferrous ion and hydrogen peroxide). It has been found that the effect of various gases bubbling on phenol degradation rate ranked in the following order: oxygen containing ozone $>$ oxygen $>$ argon $>$ nitrogen. However [9], when the argon was used for the electrode-enveloping gas with pulsed discharges on the water surface, a higher phenol decomposition rate was obtained than that for oxygen and air. But when the argon flow rate was increased from 1 to 40 $\mathrm{L} \cdot \mathrm{min}^{-1}$, there was no change in the phenol decomposition rate. On the other hand, in the case of oxygen, the decomposition rate decreased with increasing gas flow.

\subsubsection{Gas-Liquid Phase Discharge}

Electrical discharges in two-phase medium not only combine the advantages of gas-phase discharge (i.e., for ozone $\mathrm{O}_{3}$ and oxygen radical $\mathrm{O} \cdot$ formation, UV-radiation generation) with liquid-phase discharge (i.e., for hydroxyl radical $\mathrm{OH} \cdot$ and hydrogen peroxide $\mathrm{H}_{2} \mathrm{O}_{2}$ formation), but also have more advantages: increase of the gas-liquid boundary surface area which is exposed to hydrated electrons and free radicals; enhancement of the electric field at the droplet surface; concentration of the organics near the droplet surface [17]. Petr Lukes et al. [18] studied the mechanism of phenol degradation through its dependence on the gas phase and liquid phase compositions using pure argon and oxygen atmospheres above the liquid and different initial $\mathrm{pH}$ values in the aqueous solution. Phenol degradation was significantly enhanced in the hybrid-series reactor compared with the phenol removal by the single-liquid phase discharge reactor.

The hybrid series gas-liquid electrical dischargereactor was described in detail in Figure 1 [19], which was very typical. 


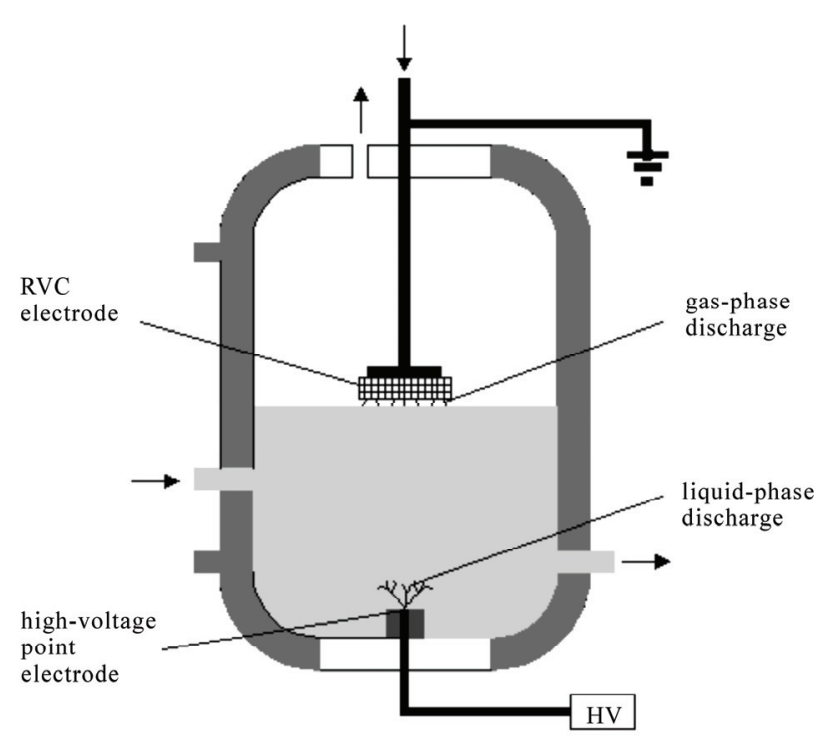

Figure 1. Hybridseriesgas-liquid electrical discharge reactor. (HV) pulse power supply.

However, liquid-phase discharge has a problem of consuming an extremely high energy. Kuroki T. et al. [20] have investigated phenol decomposition using a gasliquid interface discharge induced by an ultra-short width (similar to $600 \mathrm{~ns}$ ) pulse of high voltage. Gas bubbling was employed to enhance both convection and the gas-liquid interface area. A significant improvement in energy efficiency of phenol decomposition was achieved.

\subsection{Glow Discharge}

Glow discharge plasma (GDP) is one of them where the plasma is sustained by glow discharges across a pointed electrode and the surface of the liquid electrolyte [21].

Gao Jinzhang et al. [21-23] made a series study of the oxidative degradation of phenolic compounds (o-chlorophenol; 2, 4-dichlorophenol; 4-chlorophenol (4-CP)); in aqu- eous solution induced by plasma with submersed glow discharge has been investigated. Various influencing factors such as the initial $\mathrm{pH}$, the concentration of phenolic compounds and the catalytic action of $\mathrm{Fe}^{2+}$ were examined. It was showed that degradation of phenolic compounds can be efficiently increased in alkaline conditions with the addition of $\mathrm{Fe}^{2+}$. Liu, Y. J. et al. [24] also found that adding appropriate amounts of $\mathrm{Fe}^{2+}$ or $\mathrm{Fe}^{3+}$ to the solution was favorable for phenol degradation by plasma with submersed glow discharge. Furthermore, carbonate ions or n-butanol in the solution can decelerate the phenol removal. When the treatment time is increased and the $\mathrm{pH}$ value of the solution is decreased, leading to an increase in the phenol decomposition.

Wang L. et al. [25] investigated the degradation of bisphenol A (BPA) and simultaneous formation of hydrogen peroxide induced by glow discharge plasma in contact with a queous solution. Experimental results indicated that the BPA degradation rate was higher in sodium chloride solution than that in sodium sulfate or phosphate solutions. However, the formation rates of hydrogen peroxide were on the opposite case.

The schematic diagram of the glow discharge set-up is shown in Figure 2 [22].

\subsection{Gliding Arc Discharge}

The gliding arc discharge is a simple and inexpensive way to generate non-thermal plasma. It has a dual character of thermal and non-thermal plasma, and can involve relatively high electric powers compared with the corona discharge [26].

Ch. M. Du et al. [21-24] has designed a gliding arc reactor in their laboratory with the aim to degrade aqueous phenol solutions and 4-CP solution at atmospheric pressure. They have already made a series study on the various factors affecting the degradation efficiency, including supply voltage, electrode gap distance, and gas-liquid flow properties. The efficiency, which steeply increases when increasing the supply voltage, can reach $96 \%$ when the minimum electrode distance is fixed at $3 \mathrm{~mm}$. Experiments show that their degradation efficiency also depends on solution $\mathrm{pH}, \mathrm{Fe}^{2+}$ addition, gas nature and gas flow rate. Furthermore the chemical oxygen demand (COD) abatement of 4-CP solution with stainless steel electrode is higher than that with aluminum or brass electrode .Increasing gas-liquid mixing rate could also increase the degradation of 4-CP.They also used this method to degrade highly concentrated phenol wastewater [31], about $1000 \mathrm{mg} \cdot \mathrm{L}^{-1}$. It was found that the COD removal efficiency is very high, which can reached $88.82 \%$ after degradation.

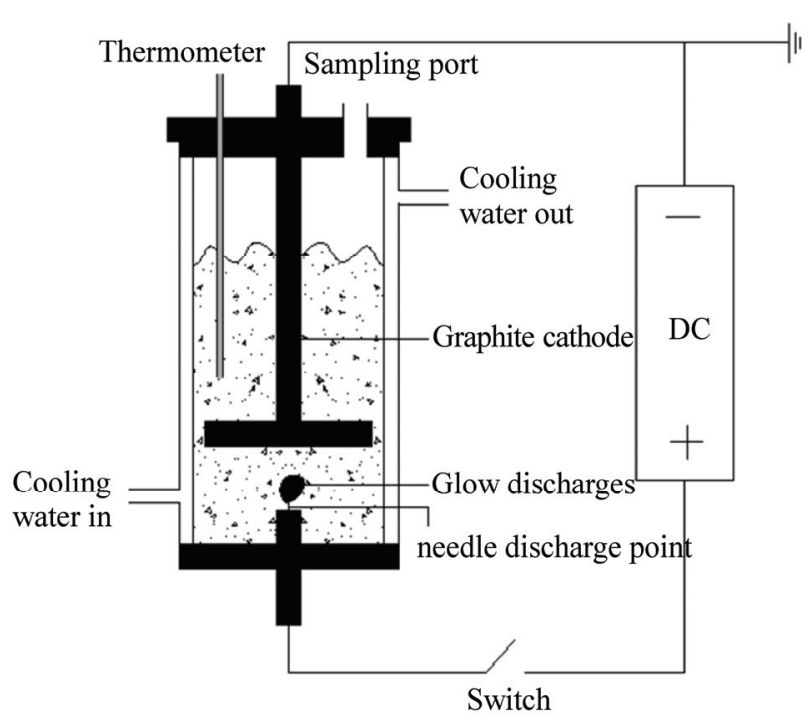

Figure 2. The sketch map of the glow discharge set-up. 


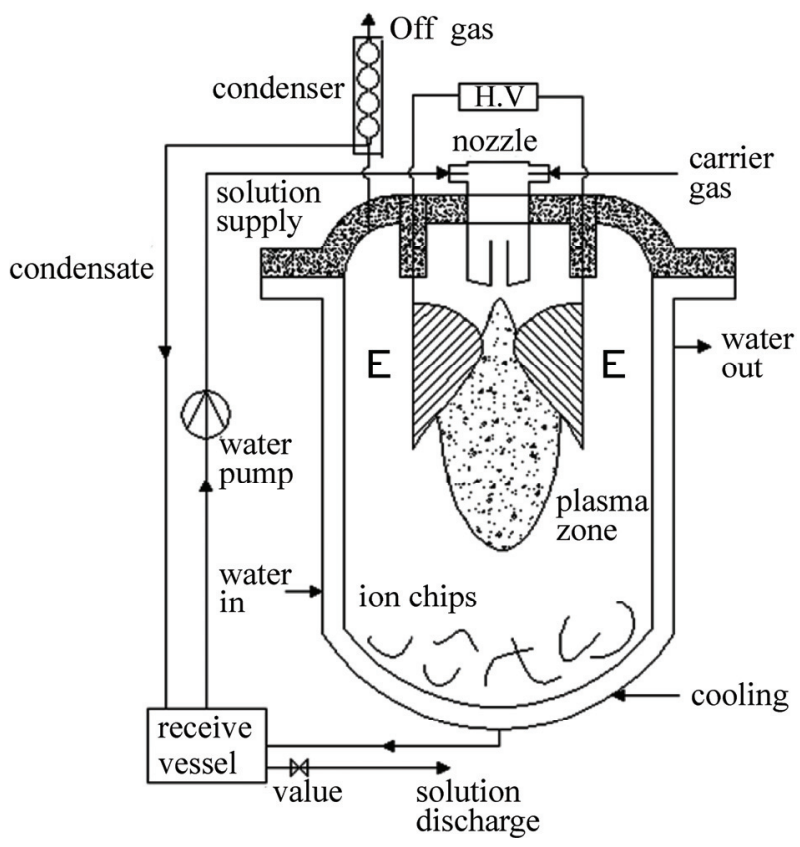

Figure 3. Scheme of the gliding arc discharge reactor.

The schematic diagram of the gliding arc discharge reactor is shown in Figure 3 [30].

\section{Mechanism}

Pyrolysis, ultraviolet photolysis, electrohydraulic, cavitation and supercritical water oxidation occur in these plasma channels when discharged, and generate various active species such as $\mathrm{OH} \cdot, \mathrm{O} \cdot \mathrm{H} \cdot \mathrm{O}_{3}$, etc [32]. Petr Lukes et al. [18] confirmed that hydroxyl radicals and ozone are the key oxidation species produced by the gas-phase discharge of the hybrid series reactor under argon and oxygen atmospheres, respectively. An electrophilic substitution reaction mechanism was proved by the significant correlation between the relative rates of oxidation of substituted phenols obtained in the hybrid series reactor and the Hammett substituent constants [28]. In conclusion, the mechanism of phenol's degradation was commonly found to be attributed mainly to the oxidation by hydroxyl radicals produced directly by the discharge.

\subsection{Mechanism of Discharge Only}

Depending on the degradation region, discharge process can be conveniently grouped into two categories of effects: 1) localized and 2) extended. Localized effects occur in the immediate vicinity of the plasma channel and include thermal oxidation within the plasma channel, vacuum UV photolysis at the surface of the plasma channel, and supercritical oxidation within the subsequent steam bubbles. On the other hand, extended effects are due to radical reactions in which active species gen- erated in the vicinity of the plasma channel expand outwardly from the circumference [33]. In different discharge types, the radical reactions in localized process are different, but in extended process are nearly the same as each other.

For the pulsed high-voltage electrical discharge in liquid, initial models of the bulk-phase corona-induced chemical reactions were reported by M. Dors et al [34]. In that study it was assumed that the pulsed corona discharge leads to the formation of hydrogen peroxide, hydroxyl radicals, and aqueous electrons through reactions (1-3) as shown in Table 1. The other major species produced by the corona reactor were assumed to be the same as those formed in radiation processes such as electron beam radiation and pulse radiolysis as indicated by the propagation and termination reactions given in Table 1. When degrading phenols, the reactions as reactions (57-68) shown in Table1.

For the pulsed high-voltage electrical discharge in gas and in gas-liquid phase $[4,6,19,35]$, ozone was first produced by gas phase discharge, then went into liquid phase to induce the radical reaction and produced $\mathrm{OH}$ radicals (reactions 56-57). Furthermore, reactions between high energetic electrons in discharge streamer and the initial molecules in aqueous solution could form $\cdot \mathrm{OH}$ (as shown in reactions 4-16 given in Table 1).

$$
\begin{gathered}
\mathrm{O}_{3}+\mathrm{H}_{2} \mathrm{O}+\mathrm{hv} \rightarrow \mathrm{H}_{2} \mathrm{O}_{2}+\mathrm{O}_{3} \\
\mathrm{H}_{2} \mathrm{O}_{2} \rightarrow 2 \mathrm{OHg}
\end{gathered}
$$

In the glow discharge, the gaseous water molecules were dissociated into positive water ions and electrons as indicated in reaction [22] (2):

$$
\mathrm{H}_{2} \mathrm{O}_{\text {gas }} \rightarrow \mathrm{H}_{2} \mathrm{O}^{+}+e^{-}
$$

The positive water ions were accelerated in the cathode-fall of the GDP and entered the solution with enough kinetic energy to break up the liquid water molecules to form the following primary species both through energy transfer and through charge transfer (Equations (3)-(5)):

$$
\begin{gathered}
\mathrm{H}_{2} \mathrm{O}^{+}+\text {cathode- fall } \rightarrow \mathrm{H}_{2} \mathrm{O}^{+^{*}} \\
\mathrm{H}_{2} \mathrm{O}^{+{ }^{*}}+n \mathrm{H}_{2} \mathrm{O} \rightarrow \mathrm{n} \bullet \mathrm{OH}+\mathrm{H}_{2} \mathrm{O}^{+}(\text {energytransfer }) \\
\mathrm{H}_{2} \mathrm{O}^{+}+\mathrm{H}_{2} \mathrm{O} \rightarrow \bullet \mathrm{OH}+\mathrm{H}_{3} \mathrm{O}^{+}(\text {ch } \arg \text { etransfer })
\end{gathered}
$$

For gliding arc plasma in humid air, it is revealed that $\mathrm{OH} \cdot$ and $\mathrm{NO}$ radicals are simultaneously, present in the discharge [36]

$$
\begin{gathered}
\mathrm{H}_{2} \mathrm{O}+\mathrm{e}^{-1} \rightarrow \mathrm{H}+\mathrm{HO} \cdot+\mathrm{e}^{-1} \\
2 \mathrm{H}_{2} \mathrm{O}+\mathrm{e}^{-1} \rightarrow \mathrm{H}_{2} \mathrm{O}_{2}+\mathrm{H}_{2}+\mathrm{e}^{-1}
\end{gathered}
$$


Table 1. The present study utilizes the basic reactions reported by M. Dors et al.

\begin{tabular}{|c|c|c|}
\hline No. & Chemical reaction & Reaction rate constant $\left[\mathrm{M}^{-1} \mathrm{~s}^{-1}\right]$ \\
\hline 1. & $\mathrm{H} 2 \mathrm{O}=\mathrm{H} \cdot+\cdot \mathrm{OH}$ & $1.7 \quad 10^{-7}$ \\
\hline 2. & $2 \mathrm{H} 2 \mathrm{O}=\mathrm{H} 2 \mathrm{O} 2+\mathrm{H} 2$ & $3.9 \quad 10^{-6}$ \\
\hline 3. & $\mathrm{H} 2 \mathrm{O}=\mathrm{H}++$ eaq $+\cdot \mathrm{OH}$ & $4.2 \quad 10^{-7}$ \\
\hline 4. & eaq $+\mathrm{H}^{\cdot}=\mathrm{H} 2+\mathrm{OH}^{-}$ & $2.5 \quad 10^{10}$ \\
\hline 5. & $\mathrm{eaq}+\cdot \mathrm{OH}=\mathrm{OH}^{-}$ & $3.01 \quad 10^{10}$ \\
\hline 6. & $\mathrm{eaq}+\mathrm{HO}_{2}=\mathrm{HO}^{-}$ & $2.01 \quad 10^{10}$ \\
\hline 7. & eaq $+\mathrm{O}_{2}^{-}=\mathrm{HO}^{-}+\mathrm{OH}^{-}$ & $1.3 \quad 10^{10}$ \\
\hline 8. & eaq $+\mathrm{H}_{2} \mathrm{O} 2=\cdot \mathrm{OH}+\mathrm{OH}^{-}$ & $1.2 \quad 10^{10}$ \\
\hline 9. & $\mathrm{eaq}+\mathrm{HO}^{-}=\mathrm{O}^{-}+\mathrm{OH}^{-}$ & $3.51 \quad 10^{9}$ \\
\hline 10. & $\mathrm{eaq}+\mathrm{O} 2=\mathrm{O}^{-}$ & $1.8 \quad 10^{10}$ \\
\hline 11. & eaq $+\mathrm{H}^{+}=\cdot \mathrm{H}$ & $2.31 \quad 10^{10}$ \\
\hline 12. & eaq $+\mathrm{H} 2 \mathrm{O}=\mathrm{OH}^{-}+\mathrm{H}^{\cdot}$ & $1.00 \quad 10^{3}$ \\
\hline 13. & $2 \mathrm{eaq}=\mathrm{H} 2+2 \mathrm{OH}^{-}$ & $4.99 \quad 10^{9}$ \\
\hline 14. & $2 \mathrm{H} \cdot=\mathrm{H} 2$ & $7.82 \quad 10^{9}$ \\
\hline 15. & $\mathrm{H} \cdot+\cdot \mathrm{OH}=\mathrm{H} 2 \mathrm{O}$ & $2.51 \quad 10^{10}$ \\
\hline 16. & $\mathrm{H}+\mathrm{HO} 2=\mathrm{H} 2 \mathrm{O} 2$ & $2.01 \quad 10^{10}$ \\
\hline 17. & $\mathrm{H}^{\cdot}+\mathrm{O}_{2}^{-}=\mathrm{HO}_{2}^{-}$ & $2.01 \quad 10^{10}$ \\
\hline 18. & $\mathrm{H} \cdot+\mathrm{H} 2 \mathrm{O} 2=\mathrm{H} 2 \mathrm{O}+\cdot \mathrm{OH}$ & $8.44 \quad 10^{6}$ \\
\hline 19. & $\mathrm{H} \cdot+\mathrm{O} 2=\mathrm{HO} 2$ & $2.11 \quad 10^{10}$ \\
\hline 20. & $\mathrm{OH}^{-}+\mathrm{H}=\mathrm{eaq}+\mathrm{H} 2 \mathrm{O}$ & $2.21 \quad 10^{7}$ \\
\hline 21. & $\cdot \mathrm{OH}+\cdot \mathrm{OH}=\mathrm{H} 2 \mathrm{O} 2$ & $5.51 \quad 10^{9}$ \\
\hline 22. & $\cdot \mathrm{OH}+\mathrm{O}^{-}=\mathrm{HO}^{-}$ & $2.01 \quad 10^{10}$ \\
\hline 23. & $\mathrm{OH}+\mathrm{HO} 2=\mathrm{O} 2+\mathrm{H} 2 \mathrm{O}$ & $6.32 \quad 10^{9}$ \\
\hline 24. & $\mathrm{OH}+\mathrm{O}^{-}=\mathrm{O} 2+\mathrm{OH}^{-}$ & $8.22 \quad 10^{9}$ \\
\hline 25. & $\mathrm{OH}+\mathrm{H}_{2} \mathrm{O} 2=\mathrm{HO} 2+\mathrm{H} 2 \mathrm{O}$ & $4.07 \quad 10^{7}$ \\
\hline 26. & $\mathrm{OH}+\mathrm{HO}_{2}^{-}=\mathrm{HO} 2+\mathrm{OH}^{-}$ & $\begin{array}{ll}7.52 & 10^{7}\end{array}$ \\
\hline 27. & $\mathrm{OH}+\mathrm{H} 2=\mathrm{H}+\mathrm{H} 2 \mathrm{O}$ & $3.82 \quad 10^{7}$ \\
\hline 28. & $\mathrm{OH}+\mathrm{OH}^{-}=\mathrm{O}^{-}+\mathrm{H} 2 \mathrm{O}$ & $1.2 \quad 10^{10}$ \\
\hline 29. & $2 \mathrm{O}^{-}=\mathrm{OH}^{-}+\mathrm{HO}_{2}^{-}$ & $1.0 \quad 10^{9}$ \\
\hline 30. & $\mathrm{O}^{-}+\mathrm{O}^{-}=\mathrm{O} 2+2 \mathrm{OH}^{-}$ & $6.02 \quad 10^{8}$ \\
\hline 31. & $\mathrm{O}^{-}+\mathrm{H} 2 \mathrm{O} 2=\mathrm{O}_{2}^{-}+\mathrm{H} 2 \mathrm{O}$ & $5.01 \quad 10^{8}$ \\
\hline 32. & $\mathrm{O}^{-}+\mathrm{HO}_{2}^{-}=\mathrm{O}^{-}+\mathrm{OH}^{-}$ & $4.01 \quad 10^{8}$ \\
\hline
\end{tabular}




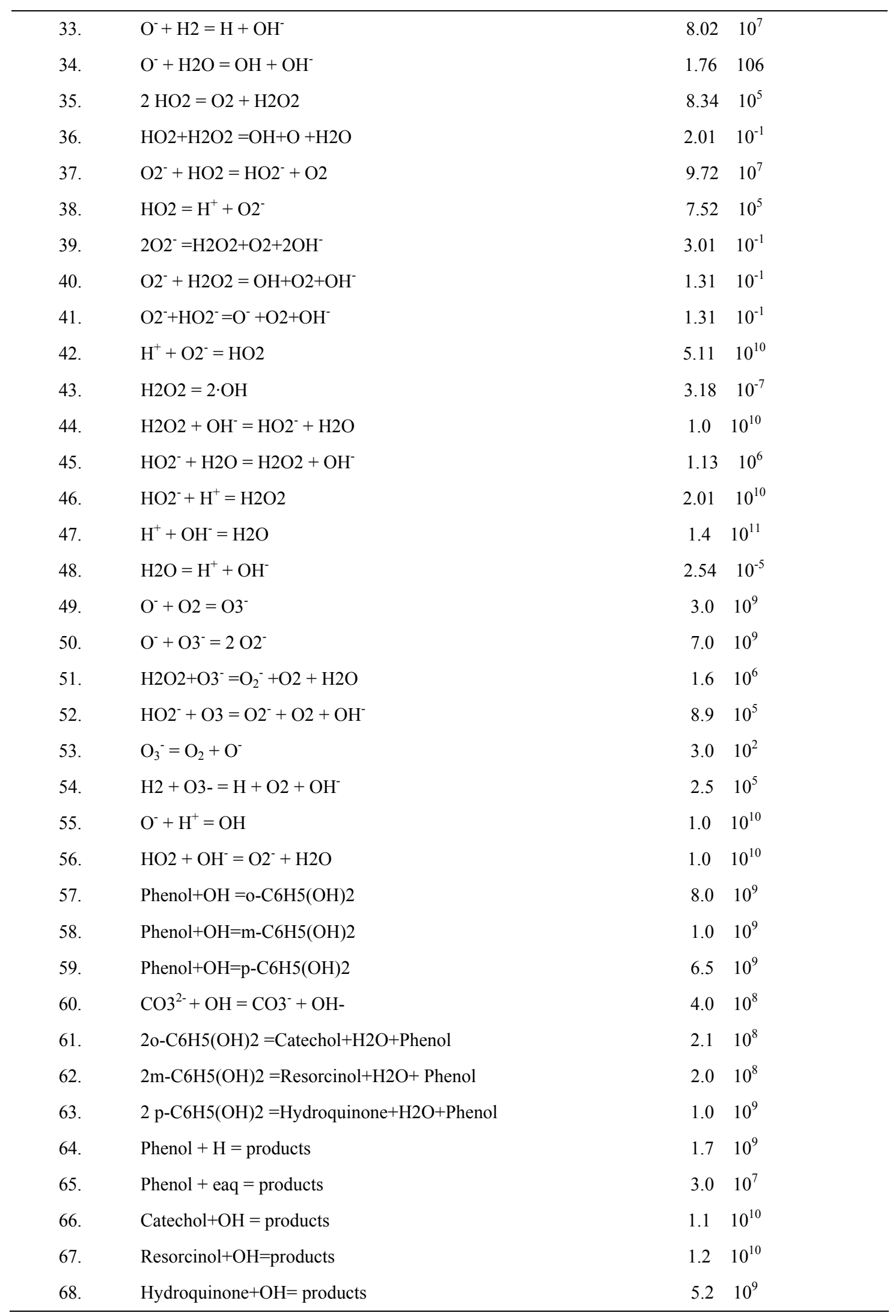




$$
\begin{gathered}
\mathrm{H}_{2} \mathrm{O}+\mathrm{e}^{-1} \rightarrow \mathrm{H}^{+}+\mathrm{HO} \cdot+\mathrm{e}_{\mathrm{aq}}{ }^{-1} \\
\mathrm{e}^{-1}+\mathrm{O}_{2} \rightarrow \mathrm{e}^{-1}+2 \mathrm{O} \\
\mathrm{O}\left({ }^{1} \mathrm{D}\right)+\mathrm{O}_{2} \rightarrow \mathrm{O}_{3} \\
\mathrm{H}+\mathrm{O}_{2} \rightarrow \mathrm{HO}_{2} \\
\mathrm{e}^{-1}+\mathrm{N}_{2} \rightarrow \mathrm{e}^{-1}+2 \mathrm{~N} \\
\mathrm{~N}_{2}+\mathrm{O} \rightarrow \mathrm{N}+\mathrm{NO} .
\end{gathered}
$$

\subsection{Intermediate Products and a Discussion of the Degradation Pathways}

In many studies $[7,37,38]$, it was revealed by high performance liquid chromatography and ionic chromatography that the main intermediates of phenol decomposition are hydroquinone, pyrocatechol, p-benzoquinone and organic acids. The $\mathrm{OH} \bullet$ radical reacts with phenol to form dihydroxycyclohexadienyl radical $\bullet_{6} \mathrm{H}_{5}(\mathrm{OH})_{2}$ (DHCHD). Under the circumstance of oxygen, oxygen will attack these radicals to produce dihydroxycyclohexadienylperoxyl (DHCHDP) radicals. The DHCHDP radical may decay in a first-order process to form catechol by elimination of a hydroperoxyl radical. $\left(\mathrm{HO}_{2} \bullet\right)_{4}$-CP [39] was mainly converted to 4-chlorocatechol, hydroquinone, 1, 4-benzoquinone, 2, 4-dichlorophenol, 5-chloro-3-nitropyrocatechol, and 4-chloro-2-nitrophenol, and then, they all degraded into organic acids, such as formic acid, acetic acid, oxalic acid, etc., which converted into $\mathrm{CO}_{2}$ and $\mathrm{H}_{2} \mathrm{O}$ finally.

The intermediate products are easily oxidized further under the action of the radicals and oxygen. The opening of the aromatic ring leads to the formation of low molecular weight compounds, mainly organic acids. DHCHDP form endoperoxides through repeated scavenges of oxygen. These very instable intermediates are decomposed by ring cleavage. The intermediate product or organic acids can also be oxidized through hydroxylation and hydration, finally forming carbon dioxide. Figure 1 shows the degradation pathway of phenol by pulsed electrical discharge in the presence of oxygen [38].

\subsection{Mechanism and Effect of Oxgen Bubbling}

The degradation rates under oxygen gas and oxygencontaining ozone bubbling were greatly improved. When oxygen was bubbled to the aqueous solution in the discharge reactor through the discharge electrode [5], the phenolic compounds in the aqueous solution were degraded through the following steps (As shown by the following equations). First, ozone was formed due to the oxygen discharge in the strong electric field. And then ozone transfered from gas bubble to the aqueous solution

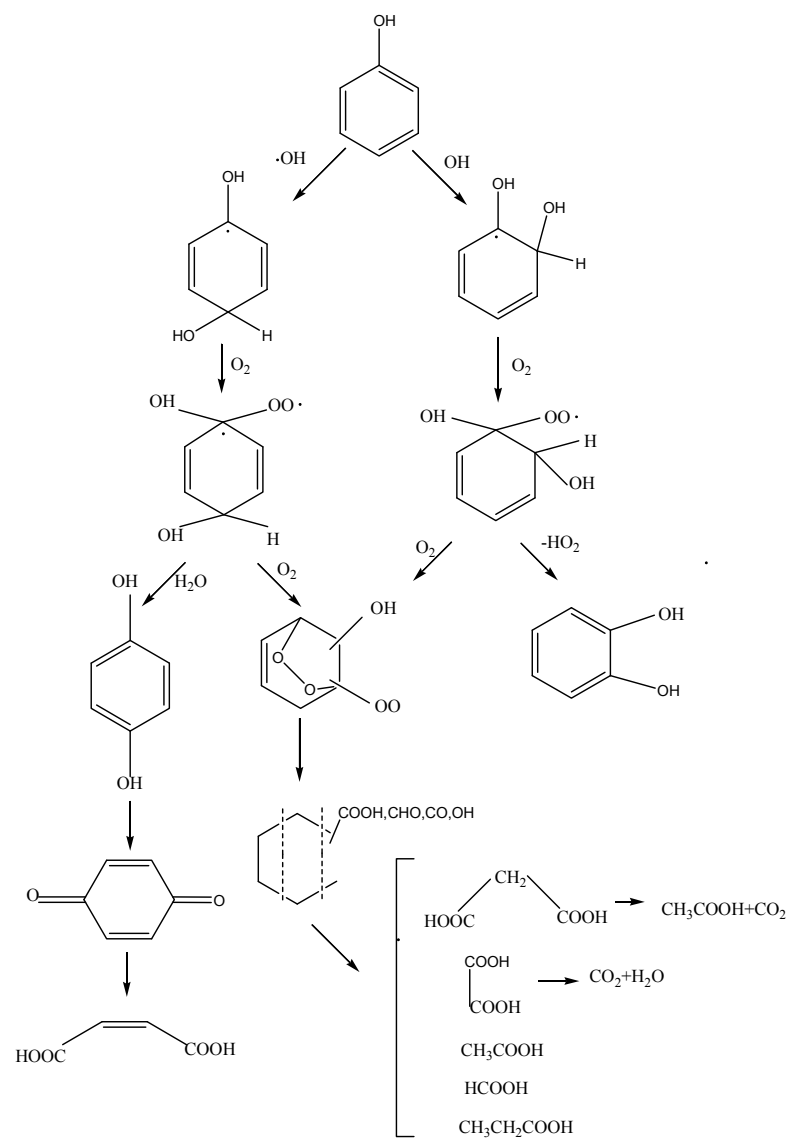

Figure 4. Degradation pathways of phenol by pulsed electrical discharges under conditions of oxygen-containing gas.

containing phenolic compounds, not only lots of $\cdot \mathrm{OH}$ radicals were produced (reaction56, 57) to degrade phenol, but also other species such as ozone, or superoxide $\left(\mathrm{O}_{2}{ }^{-}\right)$and singlet oxygen $\left({ }^{1} \mathrm{O}_{2}\right)$, participated in the chemical reactions (as shown in Table 1) [16]. The ozone and $\mathrm{OH} \cdot$ radical in the aqueous solution could react with the phenols, which was shown as Figure 4.

\subsection{Mechanism and Effect of Adding $\mathrm{H}_{2} \mathrm{O}_{2}$}

Shinta et al. [6] studied the effect of added hydrogen peroxide on phenol removal efficiency. They found that the phenol degradation rate was higher in the presence of hydrogen peroxide. It's rational to assume [10] the reaction scheme where hydroxyl radical would act as the most responsible key-species for the organic degradation in competition with the coupling to hydrogen peroxide. Anto et al. [40] found that the addition of a small amount of hydrogen peroxide greatly increased the degradation rate of phenol, in which the ultraviolet light from discharge plasma was considered to be a cause of effective degradation. However [16], since the reaction of phenol with hydrogen peroxide is very slow at the ambient tem- 
perature, the degradation process may be due to the reaction of hydroxyl radicals produced by photolysis of hydrogen peroxide, which was caused by UV radiation from electrical discharge plasma. The chemical effects of the electrical discharge plasma are due to direct photolysis (the electrical discharge plasma only), indirect photolysis (combination of chemical additives and the electrical discharge plasma) and pyrolysis destruction in plasma Channels and pyrolysis destruction in plasma Channels [41]. In conclution, it can be mainly explained by three equations (reaction $36,43,44$ ) as shown in Table 1 .

\subsection{Mechanism and Effect of Adding Iron Salts}

Grymonpre DR et al. [42] found that it was useful to add iron salts to enhance hydroxyl radical formation and increase the efficiency of phenol degradation through Fenton's reaction (Equations (3)):

$$
\begin{gathered}
\mathrm{Fe}^{2+}+\mathrm{H}_{2} \mathrm{O}_{2} \rightarrow \mathrm{Fe}^{3+}+\mathrm{HO} \cdot+\mathrm{HO}^{-} \\
\mathrm{Fe}^{3+}+\mathrm{H}_{2} \mathrm{O}_{2}+h v \rightarrow \mathrm{Fe}^{2+}+\mathrm{HO} \cdot+\mathrm{H}^{+}
\end{gathered}
$$

It can be seen that in the presence of $\mathrm{Fe} 2+$, more free radicals were produced due to the catalysis of $\mathrm{Fe} 2+$, which in turn, accelerated the reaction.

Neyens et al. [43] found that by adding $\mathrm{Fe}^{2+}$ highly influenced the phenol removal process. With the addition of $\mathrm{Fe}^{2+}$ ions the removal increased significantly from $15.45 \%$ to $94.94 \%$, but decreased if continuing. Gao Jinzhang et al. also found that the removal rate cannot be further enhanced when the concentration of $\mathrm{Fe} 2+$ is over some value (80mg.1) [22]. However Lei Wang et al. [25] demonstrated that $\mathrm{Fe}^{3+}$ exhibits a better catalytic effect than $\mathrm{Fe}^{2+}$, which is contradictory to the principles of the Fenton reaction because the reaction rate between ferric ion and hydrogen peroxide is much lower than that ferrous ion with hydrogen peroxide. They thought this phenomenon may be attributed to the following. When the aqueous BPA was exposed to GDP, the BPA initially react with hydroxyl radicals to form the intermediate products through the hydrogen abstraction or electrophilic addition to benzene ring of BPA. Lei Wang et al. [44] newly reported that when degrading phenol, one most probable way was by dihydroxycyclohexadienyl radicals, which were resulted from the attack of the hydroxyl radicals on phenol. The dihydroxycyclohexadienyl radicals then can react with $\mathrm{Fe}^{3+}$ ions, so $\mathrm{Fe}^{3+}$ exhibits a better catalytic effect than $\mathrm{Fe}^{2+}$.

\subsection{Mechanism and Effect of Adding Activated Carbon Particles on Phenol Degradation}

Activated carbon particles suspended in the liquid phase have been found to play a role in enhancing-phase co- rona reactions, in addition to their role as physical adsorbents [19].There exists also the possibility of reactions occurring on the surface of the activated carbon-induced by the electrical discharge, thus continually regenerating the activated carbon [45]. David R. et al. [46] also found that there was a strong possibility that the activated carbon participates in catalytic reactions with phenol and its primary byproducts. This occurs by adsorption of the organic molecules and possible reactions of the phenol on the carbon surface. After the carbon particles have been suspended in the solution treated by the pulsed corona, the physical properties of the carbon remain unchanged. An analysis of the carbon showed that little of the phenol initially adsorbed on the activated carbon was still present after treatment was completed.

\subsection{Mechanism and Effect of Adding $\mathrm{TiO}_{2}$ on Phenol Degradation}

Lukes et al. [47] and Hao, X L et al. [48] both studied the non-thermal plasma-induced degradation of phenols in the presence of photocatalytically active $\mathrm{TiO}_{2}$. It was found that the phenols removal efficiency with $\mathrm{TiO}_{2}$ was obviously increased. The main effect of $\mathrm{TiO}_{2}$ addition was in the utilizing of ultraviolet radiation from the plasma resulting in the photocatalytical formation of $\mathrm{OH}$ radicals on the surface of $\mathrm{TiO}_{2}$ particles and, thus, in the increase of the yield of $\mathrm{OH}$ radicals available for phenolic compounds degradation [49]. Farre et al. [50] suggested that the $\mathrm{OH}$ radical was produced by reaction of absorbed $\mathrm{H}_{2} \mathrm{O}$ molecule with photogenerated holes at the illuminated $\mathrm{TiO}_{2}$ particle. Equation (4).

$$
\begin{aligned}
& \mathrm{TiO}_{2}+\mathrm{h} v \rightarrow \mathrm{h}^{+}+e^{-} \\
& \mathrm{H}_{2} \mathrm{O}+\mathrm{h}^{+} \rightarrow \mathrm{OH} \cdot+\mathrm{H}^{+}
\end{aligned}
$$

Because when discharged, there will be much $\mathrm{O}_{3}$ produced. It can also generate $\mathrm{OH} \bullet$ radicals through the formation of an ozonide radical $\left(\mathrm{O}_{3}{ }^{\bullet-}\right)$ in the adsorption layer. Equation (5) [51].

$$
\begin{gathered}
\mathrm{TiO}_{2}+\mathrm{h} v \rightarrow \mathrm{h}^{+}+e^{-} \\
\mathrm{O}_{3}+e^{-} \rightarrow \mathrm{O}_{3} . \\
\mathrm{O}_{3} \cdot+\mathrm{H}^{+} \rightarrow \mathrm{HO}_{3} . \\
\mathrm{HO}_{3} \cdot \rightarrow \mathrm{O}_{2}+\mathrm{OH} .
\end{gathered}
$$

Hao, XL et al. compared the 4-CP removals between original $\mathrm{TiO}_{2}$ and $\mathrm{TiO}_{2}$ (used thrice), and found no obvious differences

\section{The Kinetics of Phenol Decomposition}

It is commonly believed that the phenol degradation with pulsed high-voltage discharge in aqueous solution shows a first-order kinetics: $\mathrm{C}=\mathrm{C}(0) \mathrm{e}^{(-\mathrm{kt})}\left[7,10^{-12}\right]$. 
M. Dors et al. [34] build a chemical kinetics model of phenol decomposition in water. The densities of the species participating in the chemical reactions were calculated with a set of first order, differential equations describing the chemical conversions. Results of their calculations are in good agreement with experimental and modelling results obtained by Joshi et al. Shunsuke et al. [52] studied the mechanism of phenol degradation by means of contact glow discharge electrolysis. They found that the rate of disappearance followed the first order rate law when the initial concentration of phenol was lower than $100 \mathrm{mM}$. As the initial concentration increased, the rate equation gradually deviated from the first-order and eventually shifted to zero-order above 250 $\mathrm{mM}$. Grymonpr'e et al. [54] developed models including chemical reaction kinetics, and determined the rates of function of hydrogen peroxide, hydroxyl radicals and aqueous electrons by fitting the experimental data of phenol degradation to the model. Le C. Lei et al. [55] established a kinetic model to compare three different discharge systems (pulsed spark discharge, PS; pulsed streamer corona discharge (PSCD), and pulseless corona discharge (PCD), and predict the degradation pathway. The model results are in good agreement with the experimental observations on hydrogen peroxide and ozone formation, 4-CP degradation, and intermediates formation.

\section{Combination of Several Methods with Low-Temperature Plasma Treatment}

Wen Yuezhong et al. [54] used the combination of high voltage pulse discharge and ozone as an advanced oxidation technology was used to investigate the degradation of 4-chlorophenol (4-CP) in water. The factors that affect the rate of degradation were discussed. The $1.95 \times 10^{-3}$ $\mathrm{mol} \cdot \mathrm{L}$ solutions of $4-\mathrm{CP}$ were almost completely $(96 \%)$ degraded after the discharge treatment of $30 \mathrm{~min}$.

Lukes et al. [47] investigated the non-thermal plasmainduced degradation of phenol by pulsed high-voltage discharge generated in water using point to plane geometry of electrodes in the presence of photocatalytically active $\mathrm{TiO}_{2}$. They found that the phenol removal attributed directly to the effects of plasma chemical activity of the discharge was enhanced in the presence of $\mathrm{TiO}_{2}$. Hao, $\mathrm{XL}$ et al. [48] also used this method to degrade parachlorophenol (4-CP), including other compounds phenol and methyl red in water. The experimental results showed that rate constant of 4-CP degradation, energy efficiency for 4-CP removal and TOC removal with $\mathrm{TiO}_{2}$ were obviously increased. Pulsed high-voltage discharge process with $\mathrm{TiO}_{2}$ had a promoted effect for the degradation of these pollutants under a broad range of liquid conductivity.
Bubnov et al. [55] studied the decomposing phenol in aqueous solutions under the action of an atmospheric pressure. Oxygen dielectric barrier discharged in the presence or absence of catalysts in the plasma zone, and tested two types of catalysts, $\mathrm{NiO}$ and $\mathrm{TiO}_{2}$. It was found that both materials exhibited catalytic properties. The action of $\mathrm{NiO}$ accelerated the step of phenol destruction while the action of $\mathrm{TiO}_{2}$ catalyst resulted in a more preferable composition of decomposition products and provided a higher degree of carboxylic acid conversion into carbon dioxide than the $\mathrm{NiO}$ catalyst.

\section{Conclusions}

Although non-thermal plasma produced by different types of electrical discharges have recently attracted particular interest as a promising method of water treatment without pollution or less pollution. Report on basic research are too less and not have been used to the practical application. Moreover, the final byproducts and the reaction mechanisms involved in the destruction of phenolic compounds have not been sufficiently clarified up until now. Therefore, it is need a lot of basic research for the application of technology to industrial implementation. Finally, a combination of other methods (activated carbon particles, $\mathrm{TiO}_{2}, \mathrm{H}_{2} \mathrm{O}_{2}, \mathrm{O}_{3}$, and so on) with lowtemperature plasma treatment to treat phenolic compounds will become more popular.

\section{Acknowledgments}

We gratefully acknowledge the financial support from National Natural Science Foundation of China and Shanxi Province, "2008ZDKG-78”"technology innovation project, major scientific and technology in Suzhou, Jiangsu Province.

\section{References}

[1] F. X. Zhang, "Disposal and utilizer of phenolic wastewater," Chemical Industry Press, Beijing, pp. 1-10, 1983.

[2] B. Iurascu, I. Siminiceanu, D. Vione, and M. A. Vicente, "Phenol degradation in water through a heterogeneous photo-fenton process catalyzed by fetreated laponite," Journal of Wa ter Research, pp. 1313-1322, 2009.

[3] J. R. Chen, "Chemistry of low-temperature plasma and its applications," Science press, Beijing, 2001.

[4] M. Sato, T. Tokutake, and T. Ohshima, "Aqueous phenol decomposition by pulsed discharges on the water surface," IEEE Tractions on Industry Applications, pp. 1397-140, 2008.

[5] P. Lukes and B. R. Locke, "Plasmachemical oxidation processes in a hybrid gas-liquid electrical discharge 
reactor," Journal of Physics D: Applied Physics, Vol. 38, pp. 4074-4081, 2005.

[6] S. Tomizawa and M. Tezuka, "Kinetics and mechanism of the organic degradation in aqueous solution irradiated with gaseous plasma," Journal of Plasma Chemestry and Plasma Process, Vol. 27, pp. 486-495, 2005.

[7] Y. S. Chen, X. S. Zhang, S. Chang, et al, "Study on the degradation mechanism of organic compounds in the aqueous solution by pulsed high-voltage discharge plasma," Acta Scientiae Circumstantiae, Vol. 25, pp. 113-116, 2005.

[8] L. R. Grabowski, E. M. van Veldhuizen, A. J. M. Pemen, and W. R. Rutgers, "Corona above water reactor for systematic study of aqueous phenol degradation," Plasma Chemistry and Plasma Processing, Vol. 26, pp. 3-17, 2006.

[9] B. Sun, M. Sato, J. S. Clements, "Oxidative processes occurring when pulsed high voltage discharges degrade phenol in aqueous solution," Journal Envionment Science, Vol. 34, pp. 509-513, 2000.

[10] S. Kunitomo and B. Sun, "Removal of phenol in water by pulsed high voltage discharge," Journal of Pulsed Power Plasma Science, IEEE ,Vol. 6, pp. 1138-1141, 2001.

[11] I. Suarasan and L. Ghizdavu, "Experimental characterization of multipoint corona discharge devices for direct ozonization of liquids," Journal of Electrostatics, Vol. 54, pp. 207-214, 2002.

[12] F. Z. Wang, J. Li, Wu Yan, Wang Huijuan, and Li Guofeng, "Degradation of phenol in aqueous solution by high voltage pulsed discharge plasma," High Voltage Engineering, Vol. 33, pp. 124-127,2007.

[13] Y. S. Chen, X. S. Zhang and W. K. Yuan, "A preliminary study of pulsed high-voltage corona discharge plasma for the degradation of phenol in aqueous solution," Acta Scientiae Circumstantiae,Vol. 22, pp. 566-569, 2002.

[14] Y. S. Chen, Y. S. Chen, Y. C. Dai, and W. K. Yuan, "Degradation of 4-chlorophenol in aqueous solution with pulsed high-voltage discharge plasma," Journal of Chemical Industry and Engineering, Vol. 9, pp. 12691273, 2003.

[15] Y. S. Chen, Y. S. Chen, and Y. C. Dai, "Pulsed high-voltage discharge plasma for degradation of phenol in aqueous solution," Separation and Purification Technology, Vol. 34, pp. 5-12, 2004.

[16] Y. J. Shen, L. C. Lei, X. W. Zhang, M. G. Zhou, and Y. Zhang, "Effect of various gases and chemical catalysts on phenol degradation pathways by pulsed electrical discharges," Journal of Hazardous Materials, Vol. 150, pp. 713-722, 2008

[17] P. Lukes, A. T. Appleton, and B. R. Locke, "Hydrogen peroxide and ozone formation in hybrid-gas-liquid electrical discharge reactors," IEEE Tractions onIndustry Applications, Vol. 40, No. 1, pp. 60-67, 2004.

[18] P. Lukes and B. R. Locke, "Plasmachemical oxidation processes in a hybrid gas-liquid electrical dischar- gereactor," Physics D: Applied Physics, Vol. 38, pp. 4074-4081, 2005.

[19] P. Lukes and B. R. Locke, "Degradation of substituted phenols in a hybrid gas-liquid electrical discharge reactor," Industrial \& Engineering Chemistry Research, Vol. 44, pp. 2921-2930, 2005.

[20] T. Kuroki, K. Yoshida, and Watanabe, "Decomposition of trace phenol in solution using gas-liquid interface discharge," Japaese Joural of Applied Physics Part 1-Regular Papers Brief Communications \& Review Papers, Vol. 45, pp. 4296-4300, 2006.

[21] Y. Q. Mo, L. M. Pu, H. G. Liang, J. Zhao, Q. Zhang, J. Z. Gao, "Degradation of o-chlor-ophenol in aqueous solution by contact glow discharge electrolysis," Journal of Gansu Agricultural University, Vol. 40, 2005.

[22] L. M. Pu, J. Z. Gao, W. Yang, Y. Li, J. Yu , and D. L. Huang, "Oxidative degradation of 4-chlorophenol in aqueous induced by plasma with submersed glow discharge electrolysis," Plasma Science \& Technology, Vol. 75, 2005.

[23] Q. F. Lu, J. Yu, J. Z. Gao, "Degradation of 2,4dichlorophenol by using glow discharge eclectrolysis," Journal of Hazardous Mdterials, Vol. B136, pp. 526-531, 2006

[24] Y. J. Liu and X. Z. Jiang, "Phenol degradation by a nonpulsed diaphragm glow discharge in an aqueous solution," Environmental Science \& Technology, Vol. 39, pp. 8512-8517, 2005.

[25] L. Wang, X. Z. Jiang, and Y. J. Liu, "Degradation of bisphenol A and formation of hydrogen peroxide induced by glow discharge plasma in aqueous solutions," Journal of Hazardous Materials, Vol. 154, pp. 1106-1114, 2008.

[26] A. Czenichowski, Pure and Applied Chemistry, Vol. 66, pp. 1301, 1994.

[27] C. M. Du, J. H. Yan, X. D. Li, Z. Bo, X. D. Sun, and K. F. Cen, "Gas-liquid two phase gliding arc plasma for degradation of phenol in aqueous solution," Journal of Engineering Thermophysics, 2005.

[28] C. M. Du, J. H. Yan, X. D. Li, K. F. Cen, M. J. Ni, Y. L. Wei, and B. G. Cheron, "Treatment of 4-chlorophenol solution by gas-liquid gliding arc discharge," Proceedings of the CSEE, Vol. 13, 2006.

[29] J. H. Yan, C. M. Du, X. D. Li, et al., "Degradation of phenol in aqueous solutions by gas-liquid gliding arc discharges," Plasma Chemistry and Plasma Processing, Vol. 26, pp. 31-41, 2006.

[30] C. M. Du, J. H. Yan, and B. G. Cheron, "Degradation of 4-chlo-rophenol using a gas-liquid gliding arc discharge plasma reactor," Plasma Chemistry and Plasma Processing, Vol. 27, pp. 635-646, 2007.

[31] X. D. Sun, J. H. Yan, X. D. Li, C. M. Du, and J. L. Yang, "The study of circulating degradation of highly concentrated phenol wastewater by gas-liquid phase gliding arc discharge," Energy Engineering, Vol. 1, pp 32-35, 2006. 
[32] Power Plasma Science, IEEE, Vol. 6, pp. 1138-1141, 2001.

[33] D. R. Grymonpre, “An experimental and theoretical analysis of phenol degradation by Pulsed corona discharge," The Florida State University, Doctor thesis, USA, 2001.

[34] M. Dors, G. V. Nichipor, and J. Mizeraczyk, "Modeling of phenol decomposition induced by pulsed corona discharge in water," Dielectric Liquids, IEEE International Conference, 2005.

[35] W. F. L. M. Hoeben, "Pulsed corona-induced degradation of organic materials in water," $\mathrm{PhD}$ thesis, Technische Universiteit Eindhoven, June 2000.

[36] Y. N. Liu, J. H. Yan, X. D. Li, C. M. Du, and S. L. Dai, "Progress in research of application of Gl iding arc discharge to wastewater treatment," High Voltage Engineering, Vol. 33, pp. 159-162, 2007.

[37] D. R. Grymonpre, "An experimental and theoretical analysis of phenol degradation by Pulsed corona discharge," The Florida State University, Doctor thesis, USA, 2001.

[38] A. A. Joshi, B. R. Locke, P. Arce, and W. C. Finney, "Formation of hydroxyl radicals, hydrogen peroxide and aqueous electrons by pulsed streamer corona discharge in aqueous solution," Journal of Hazardous Materials, Vol. 41, pp. 3-30, 1995.

[39] NIST Chemical Kinetics Database, http://kinetics.nist. gov/

[40] A. T. Sugiarto and M. Sato, "Pulsed plasma processing of organic compounds in aqueous solution," Thin olid Films, Vol. 386, pp. 295-299, 2001.

[41] C. R. Huang and H. Y. Shu, "The reaction kinetics, decomposition pathways and intermediate formations of phenol in ozonation,UV/O, and UV/H2O2 processes," Journal of Hazardous Materials, Vol. 41, pp. 47-64, 1995.

[42] D. R. Grymonpre, A. K. Sharma, W. C. A. Finney, and B. R. Locke, "The role of fentons reaction in aqueous phase pulsed streamer corona reaetors," Chemical Engineering Journal, Vol. 82, pp. 189-207, 2001.

[43] E. Neyens and J. Baeyens, "A review of classic fentons peroxidation as an advanced oxidation technique,". Journal of Hazardous Materials, Vol. 98, pp. 33-55, 2003.

[44] L. Wang and X. Z. Jiang, "Unusual catalytic effects of iron salts on phenol degradation by glow discharge plasma in aqueous solution," Journal of Hazardous Materials, Vol. 161, pp. 926-932, 2009.
[45] D. R. Grymonpre , W. C. Finney, and B. R. Locke, "Aqueous-phase pulsed streamer corona reactor using suspended activated carbon particles for phenol oxidation: model-data comparison," Chemical Engineering Science, Vol. 54, pp. 3095-3105, 1999.

[46] D. R. Grymonpre, W. C. Finney, R. J. Clark, and B.R. Locke, "Suspended activated carbonparticles and ozone formation in aqueous-phase pulsed corona discharge reactors," Industrial \& Engineering Chemistry Research, Vol. 420, pp. 5117-5134, 2003.

[47] P. Lukes, M. Clupek, P. Sunka, et al, "Degradation of phenol by underwater pulsed corona discharge in combination with $\mathrm{TiO} 2$ photocatalysis," Research on Chenical Intermediates, Vol. 31, 2004.

[48] X. L. Hao, M. H. Zhou, and L. C. Lei, "Non-thermal plasma-induced photocatalytic degradation of 4-chlorophenol in water," Journal of Hazardous Materials, Vol. 141, pp. 475-482, 2007.

[49] H. J. Wang, J. Li, X. Quan, and Y. Wu, "Enhanced generation of oxidative species and phenol degradation in a discharge plasma system coupled with $\mathrm{TiO} 2$ photocatalysis," Applied Catalysis B: Environmental, Vol. 83, pp. 72-77, 2008.

[50] M. J. Farre, M. I. Franch, S. Malato, J. Ayllon, J. Peral, and X. Domenech, Chemosphere, 2004.

[51] L. Sanchez, J. Peral, and X. Domenech, Applied Catalysis B: Environmental,Vol.19, pp. 59-65, 1998.

[52] H. Tomizawa and M. Tezuka, " Kinetics and mechanism of the organic degradation in aqueous solution irradiated with gaseous plasma," Plasma Chemistry and Plasma Processing, Vol. 27, 2007.

[53] L. C. Lei, Y. Zhang, X. W. Zhang, Y. X. Du, Q. Z. Dai, and S. Han, "Degradation performance of 4-chlorophenol as a typical organic pollutant by a pulsed high voltage discharge system," Applied Chemistry, Vol. 46, pp. 5469-5477, 2007.

[54] Y. Z. Wen, X. Z. Jiang, and W. P. Liu, "Degradation of 4-Chlorophenol in Aqueous Solution by high-voltage pulsed discharge-ozone technology," Environmental Science, Vol. 23, pp. 73-76, 2002.

[55] A. G. Bubnov, E. Y. Burova, V. I. Grinevich, et al., "Comparative actions of $\mathrm{NiO}$ and $\mathrm{TiO} 2$ catalysts on the destruction of phenol and its derivatives in a dielectric barrier discharge," Plasma Chemisry and Plasma Processing, Vol. 27, pp. 177-187, 2007. 